\title{
Effects of silver nanoparticles and multi-walled carbon nanotubes on certain aquatic species
}

\author{
A. Sairam Kishore ${ }^{1}$, S. Ayyappan ${ }^{2}$, G. Chandrasehar ${ }^{2}$, R.A. Gopi ${ }^{2}$, \\ P. Balakrishna Murthy ${ }^{3}$ \\ ${ }^{1}$ Laila Neutraceuticals, Vijayawada, Andhrapradesh, India \\ ${ }^{2}$ Department of Ecotoxicology, International Institute of Biotechnology and Toxicology (IIBAT) \\ Kanchipuram District, Padappai, Chennai, India. PIN - 601301. \\ ${ }^{3}$ Former Director, IIBAT, Chennai, India
}

\begin{abstract}
Aquatic toxicity studies with two different sizes of multi-walled carbon nanotubes (MWCNTS) and silver (Ag) nanoparticles were conducted on Rainbow trout fish Oncorhynchus mykiss, water flea Daphnia magna, and green algae Pseudokirchneriella subcapitata as model organisms. Author ${ }^{(I)}$ along with co-authors ${ }^{(2,3)}$ conducted this research work at IIBAT as a part of PhD. The results of these studies indicated that MWCNTs are low concern whereas, silver nanoparticles are of high concern to the aquatic species tested (Rainbow trout fish, Water flea and Green alga). The present aquatic studies demonstrated the hazard potential of silver nanoparticles to the aquatic species, following acute exposure and calls for surveillance on the impact of the wide release of nanomaterials into the environment.
\end{abstract}

Key words: Aquatic toxicity, Silver nanoparticles, MWCNT, Silver nanoparticles, Rainbow trout fish, Water flea Daphnia, Green alga, Nanotechnology.

\section{Introduction}

The rapid growth of nanotechnology is leading to increased accidental and purposeful release of nanoparticles into the environment. Released into air, water or soil leads to their access to a variety of species ranging from single celled organisms such as bacteria and algae to more complex vertebrates such as fish and aquatic mammals. Impact on any of the organisms within the ecosystem may have consequences on the remainder of the ecosystem by affecting food chains and interactions between different species. In order to ascertain which environments and species are at high risk due to significant exposure, it is important to assess the effects of nanoparticles. Hence, overall impacts and risks of engineered nanoparticles released into the environment need to be addressed (Colvin 2003; Oberdorster et al. 2005). However, very few studies have addressed the ecotoxicological and environmental effects of direct and indirect exposure to nanoparticles, and thus far, no clear guidelines have been established to quantify these effects (US EPA 2007). Oberdorster et al. (2006) were the first to document that carbon-based nanomaterials can endanger the health of aquatic organisms. This study showed that stable buckminsterfullerene $\left(\mathrm{C}_{60}\right)$ water suspensions $\left(\mathrm{nC}_{60} /\right.$ aq, no solvent was used) at 2.5 and $5 \mathrm{mg} \mathrm{l}^{-1}$ could delay molting and reduce offspring production in Daphnia magna. Similarly, not much information on the ecotoxicological studies of carbon nanotubes (CNTs) is available in literature, although the toxicity of single-walled carbon nanotube (SWNT) based nanomaterials to an estuarine copepod (Amphiascus tenuiremis), Daphnia, and Rainbow trout fish was reported (Templeton et al. 2006; Roberts et al. 2007; Smith et al. 2007). Hund-Rinke and Simon (2006) were first to document the toxicity of $\mathrm{TiO}_{2} \mathrm{NPs}$ to Daphnia and green alga (Desmodesmus subspicatus). Growth inhibition of algae and immobilization of Daphnia were observed overtly for $\mathrm{TiO}_{2}$ NPs. Adams et al. (2006) compared the ecotoxicity of $\mathrm{TiO}_{2}, \mathrm{ZnO}$, and $\mathrm{SiO}_{2}$ nanoparticles suspended in water using gram-negative Escherichia coli and Gram-positive Bacillus subtilis as two model bacterial species. This study revealed that $\mathrm{ZnO}$ was the nanomaterial most toxic to Bacillus subtilis. Experiments on embryonic zebrafish demonstrated similar results; $\mathrm{ZnO}$ NPs were more toxic than $\mathrm{TiO}_{2}$ or $\mathrm{Al}_{2} \mathrm{O}_{3}$ NPs ( $\mathrm{Zhu}$ et al. 2008). Although more information about the ecotoxicity of NPs continues to become available, because studies have been conducted on a limited number of manufactured nanomaterials, and in a small number of aquatic species (US EPA 2007), a significant knowledge gap still exists regarding various aspects of environmental toxicology related to NPs (SCENIHR 2005). Thus, proactive research on the potential environmental and health impacts of NPs is crucial to protect the environment and to ensure a sustainable nanotechnology industry that is bound to expand rapidly in the twenty first century. (Colvin 2003; Service RF 2000, 2003; Nel et al. 2006). In order to add information to this knowledge gap, we used Oncorhynchus mykiss, Daphnia magna and Pseudokirchneriella subcapitata as model organisms to conduct aquatic studies on two different sizes of multi-walled carbon nanotubes and silver $(\mathrm{Ag})$ nanoparticles the results of which are reported in this communication. 


\subsection{Nanomaterials}

\section{Materials And Methods}

Two different sizes of Silver (Ag) nanoparticles (Silver 1 -: 30-50 nm; Stock No. \# 0477YD) and (Silver 2 -: $10 \mathrm{~nm}$; Stock No. \# 0478YD) and multi-walled carbon nanotubes (MWCNT 1 -: 5-8 microns in length with 3-8 nm inside diameter and outside diameter of $140+/-30 \mathrm{~nm}$; Product No. 659258), (MWCNT 2 -: 1-10 microns in length with 2-6 nm inside diameter and outside diameter of 10-15 nm; Product No. 677248) were purchased respectively from Nanoamor Inc. Houston, USA from Sigma Aldrich, USA.

\subsection{Particle-types and physico-chemical characterization}

The silver nanoparticles and multi-walled carbon nanotubes were synthesized respectively by wet chemistry method and catalytic chemical vapor deposition (CCVD). The manufacturer specifications for nanomaterial characterization were confirmed by the following techniques. Nanomaterials characteristics were assessed in the as-synthesized form prior to experimental use.

\subsection{Size}

The size and morphology of silver nanoparticles were evaluated by transmission electron microscopy (TEM). Model: TECNAI-12, TEM at accelerating voltages from 100-120 kilovolts and associated imaging software. The nanomaterials were drop cast onto formvar-carbon coated TEM grids 29 at concentrations of typically $1 \mathrm{mg} \mathrm{ml}^{-1}$ or less and dried before imaging in TEM. Information on mean size was calculated from a random field of view in addition to images that show general morphology of the nanomaterials. Over 100 particles were counted and measured to determine average sizes and size distributions.

The size of multi-walled carbon nanotubes was determined by scanning electron microscopy (SEM) which produces images by rastering a primary electron beam across the sample surface while detecting secondary or backscattered electrons that are emitted from the surface. This results in images of 3-D quality and greater resolution. SEM was performed on Hitachi S-520 at an accelerating voltage of 10000 volts after depositing the samples onto aluminum stubs with double-sided carbon adhesive tape (Sairam Kishore et al., 2009).

\subsection{Dynamic light scattering}

Particle size measurements in water was determined with dynamic light scattering (DLS) as described by Murdock et al., 2008 on a Malvern Instruments Zetasizer. Average size was calculated by the software from the intensity, volume and number distributions measured.

\subsection{Acute toxicity test in fish}

Acute toxicity (static test) to rainbow trout fish, Oncorhynchus mykiss was conducted as per OECD 203 testing guidelines (OECD, 1992). The objective of this experiment was to evaluate the toxicity $\left(\mathrm{LC}_{50}\right)$ of two different sizes of MWCNT and silver nanoparticles. Rainbow trout fish was purchased from a commercial supplier M/s. KDHP Hills and Plantation, Munnar, Kerala, India. At fish farm, the fish were packed in the polythene bags containing oxygenated water and transferred into an insulated ice-box which contains ice gel packs to maintain the temperature of $13-17^{\circ} \mathrm{C}$ and transported to the testing laboratory within $18 \mathrm{hr}$. On receipt, fish were maintained in the same water for 5-6 hr to reduce the transportation stress. Then fish were released in cold water of temperature ranging from 13 to $17^{\circ} \mathrm{C}$. Fish were physically examined for its health condition and found to be in healthy condition (free from stress). Fish were fed daily twice with commercially purchased from Manimangalam Fish Farm - Beryl Aqua Limited, Padappai, India (manufactured by C.P. Classic Aquarium Fish Food, manufactured by S.W.T. Co., Ltd., Thailand) fish feed approximately $200 \mathrm{mg}$ feed/fish/day. Fish was quarantined for 12 days in the laboratory conditions prior to the experiment. The sizes of the fish used for the experiment were 4 to $6 \mathrm{~cm}$.

Blended water (Mixture of well water and reverse osmosis water in the ratio of 1:1) was used as exposure medium. The sizes of the fish used for the experiment were 4 to $6 \mathrm{~cm}$ and transferred into five glass aquaria (10 fish/ 301 tank with 201 of exposure medium) and allowed to acclimatization under controlled laboratory conditions (temperature: $15 \pm 2^{\circ} \mathrm{C}$; photo period: $12 \mathrm{hr}$ light/12 hr dark) for seven days prior to commencement of the experiment. In order to minimise the risk of the test compound being absorbed onto the food or faecal material, and to maintain consistent water quality, fish were not fed $24 \mathrm{hr}$ prior to, or during the experimental period. The temperature, $\mathrm{pH}$ and dissolved oxygen of the blended water (exposure medium) were monitored during the course of the experimental period for various treatments. Hardness and conductivity of the water (exposure medium) was analyzed prior to commencement of the experiment.

All the water quality parameters viz., $\mathrm{pH}(6-8.5)$, dissolved oxygen $\left(>3 \mathrm{mg} \mathrm{l}^{-1}\right)$ and laboratory conditions were within normal limits during the course of the experimental period. $\mathrm{pH}$, temperature, conductivity and dissolved oxygen were analyzed using instruments Eutech pH Testr 30, LaMotte Series-CON 
5-WC and Lovibond-Sensodirect Oxi200 respectively and total hardness was estimated by EDTA method (APHA et al., 1975).

\subsubsection{Experimental Design}

Desired quantity of the test material was weighed and suspended in the exposure medium. The fish were exposed to different concentrations $\left(0.01,0.1,1.0,10\right.$ and $\left.100 \mathrm{mg} \mathrm{l}^{-1}\right)$ of each test material (two different sizes of silver nano particles and MWCNT) for a period of $96 \mathrm{hr}$. Control group of fish were exposed to exposure medium alone.

Observations for mortality and abnormal behaviour were made twice on the first day (approximately 3 $\mathrm{hr}$ and $6 \mathrm{hr}$ after treatment) of the exposure, thereafter at the end of every $24 \mathrm{hr}$ until $96 \mathrm{hr}$, when the experiment was terminated.

\subsection{Acute immobilisation test in Daphnia}

The acute Immobilisation test to the Daphnia magna was conducted as per OECD 202 testing guidelines (OECD, 2004). The objective of this study was to evaluate the toxicity $\left(\mathrm{EC}_{50}\right)$ of two different sizes of MWCNT and silver nanoparticles. Daphnia magna primary culture was procured from M/s. Marinco Bioassay lab, U.S.A and subcultures were maintained in IIBAT laboratory.

\subsubsection{Test conditions}

Brood daphnids (5/test chamber) were acclimatized in M4 medium (temperature: $20 \pm 2^{\circ} \mathrm{C}$; photoperiod: $16 \mathrm{hr}$ light and $8 \mathrm{hr}$ dark) prior to start of the test. Daphnids used in this study was $24 \mathrm{hr}$ old i.e, the offsprings produced by parent Daphnia. Four replicates were maintained for each test concentration and control group. The daphnids were starved during the course of the experiment. Each test beaker was filled with $50 \mathrm{~mL}$ dilution water (M4 medium). Temperature, $\mathrm{pH}$ and dissolved oxygen of the M4 medium were recorded both at the beginning and end of the experiment for all the test concentrations as well as control. Conductivity and hardness of the M4 medium was recorded prior to the commencement of the experiment. All the water quality parameters viz., $\mathrm{pH}(6-9)$, dissolved oxygen $\left(>3 \mathrm{mg} \mathrm{l}^{-1}\right)$ and laboratory conditions were within normal limits during the exposure. During the experiment, the test medium was not aerated. Six days aerated medium was used for the Daphnia study. $\mathrm{pH}$, temperature, conductivity and dissolved oxygen were analyzed using instruments Eutech pH Testr 30, LaMotte Series-CON 5-WC and Lovibond-Sensodirect Oxi200 respectively and total hardness was estimated by EDTA method (APHA et al., 1975).

\subsubsection{Experimental Design}

Desired quantity of the test material was weighed and suspended in exposure medium (M4 medium). Daphnids were exposed to each test material (two different sizes of silver nano particles and MWCNT) at different concentration of $0.01,0.1,1.0,10$ and $100 \mathrm{mg} \mathrm{l}^{-1}$ in 4 batches (replicates), each batch consisting of 5 daphnids (total 20 daphnids/concentration). Concurrently, control (without test material) was maintained each with 20 daphnids in 4 batches. At the end of $24 \mathrm{hr}$ and $48 \mathrm{hr}$, number of daphnids immobilised in various treatments and control were counted.

\subsection{Alga Growth Inhibition Test}

The acute toxicity to the green alga, Pseudokirchneriella subcapitata was conducted as per OECD guideline 201 (OECD, 2006) under static conditions. The objective of this study was to estimate the toxicity of two different sizes of MWCNT and silver nanoparticles to P. subcapitata (Strain: SAG 61.81 procured from SAG: Collection of Algal Cultures, Institute of Plant Physiology, University of Göttingen, Germany).

\subsubsection{Test conditions}

The control and nanoparticle treated flasks were shaken continuously around $135 \mathrm{rpm}$ in shaker incubator for $72 \mathrm{hr}$ under a continuous illumination of $7500 \pm 500$ lux light intensity at $22-24^{\circ} \mathrm{C}$. During the course of the experiment, control and treated flasks were randomly repositioned in the shaker incubator daily in the forenoon and afternoon to get uniform light intensity.

\subsubsection{Pre-culture}

Pseudokirchneriella subcapitata were precultured 3 days before initiation of the experiment. The inoculated flasks were kept in a shaker incubator and maintained at 22 to $24^{\circ} \mathrm{C}$ at a continuous illumination of $6500-7500$ lux light intensity. After 3 days, the culture was examined under microscope to check for any abnormality or microbial contamination and used for the study.

\subsubsection{Test procedure}


Alga was exposed to each test material (Silver nanoparticles and MWCNT of two different sizes) at different concentrations of $0.01,0.1,1.0,10$ and $100 \mathrm{mg} \mathrm{l}^{-1}$ in OECD TG 201 medium and control in three replicates. The control and treated flasks were inoculated with $100 \mu \mathrm{l}$ of 3 days old pre-culture of P. subcapitata to obtain an initial cell concentration of $1 \times 10^{4}$ cells $/ \mathrm{mL}$. The concentrations of P. subcapitata (cells $/ \mathrm{mL}$ ) were visually counted under the microscope using an Improved Neubaur's Haemocytometer at $24 \mathrm{hr}, 48 \mathrm{hr}$ and $72 \mathrm{hr}$ intervals after inoculation.

\subsection{Data evaluation}

$\mathrm{LC}_{50}$ and $\mathrm{EC}_{50}$ (with $95 \%$ confidence limits), LOEC and NOEC of silver nano particles and MWCNT on test species were calculated using TOXSTAT 3.5 software version.

\subsection{Nanomaterial physico-chemical characterization}

\section{Results}

\subsubsection{Size}

Transmission electron micrograph analysis revealed the average size of Silver 1 is $40 \pm 10 \mathrm{~nm}$ and Silver 2 is $10 \mathrm{~nm}$ (Fig $1 \&$ 2). Similarly, average size of the MWCNT 1 is $166 \mathrm{~nm}$ and MWCNT 2 is $100 \mathrm{~nm}$ in SEM (Fig $3 \& 4)$.

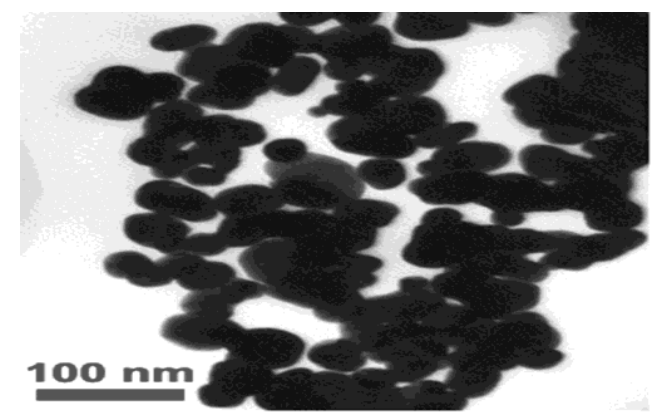

Figure 1: Transmission electron micrograph (TEM) of silver 1 nanoparticles

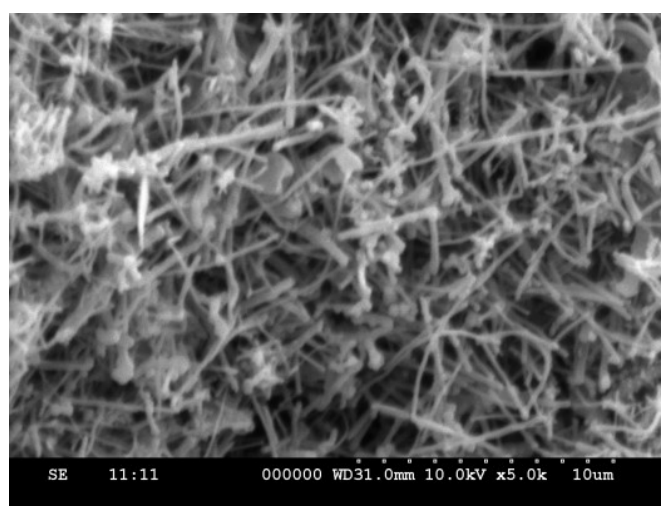

Figure 3: Scanning electron micrograph (SEM) of MWCNT1 nanoparticles

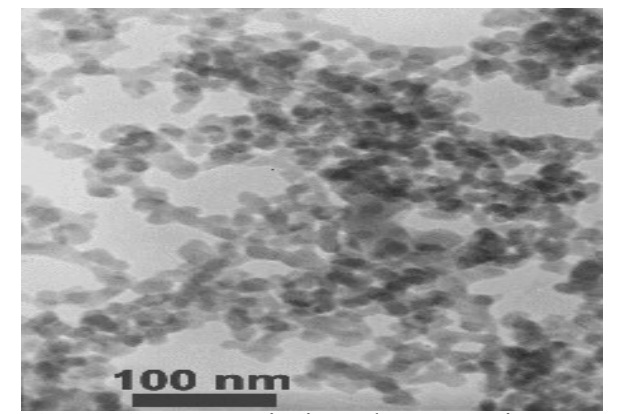

Figure 2: Transmission electron micrograph (TEM) of silver 2 nanoparticles

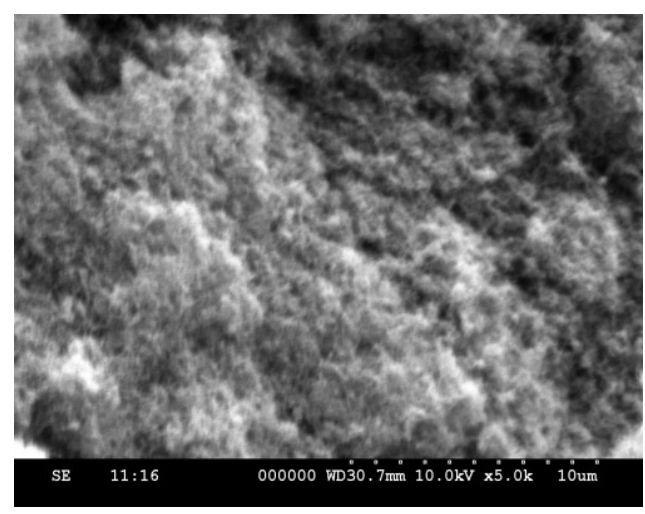

Figure 4: Scanning electron micrograph (SEM) of MWCNT 2 nanoparticles

\subsubsection{Dynamic light scattering}

The average size of MWCNT 1 in water is $901 \mathrm{~nm}$ and $554 \mathrm{~nm}$ for MWCNT 2. Similarly, silver nanoparticles 1 DLS revealed results revealed average size of $70 \mathrm{~nm}$ and silver nanoparticles 2 showed average size of $22 \mathrm{~nm}$ in water (Table-1). 
TABLE 1: Nanomaterial size measurements in water

\begin{tabular}{|l|l|}
\hline Nanomaterial & Average size in water \\
\hline $\begin{array}{l}\text { MWCNT 1 } \\
\text { O.D.X I.D X L: } 110-170 \mathrm{~nm} \times 3-8 \mathrm{~nm} \times 5-9\end{array}$ & $901 \mathrm{~nm}$ \\
$\mu \mathrm{m})$ & \\
\hline $\begin{array}{l}\text { MWCNT 2 } \\
(\text { O.D. } \times \text { I.D. } \times \text { L } 10-15 \mathrm{~nm} \times 2-6 \mathrm{~nm} \times 0.1-10 \\
\mu \mathrm{m})\end{array}$ & $554 \mathrm{~nm}$ \\
\hline Nano silver $-1(30-50 \mathrm{~nm})$ & $70 \mathrm{~nm}$ \\
\hline Nano silver $-2(10 \mathrm{~nm})$ & $22 \mathrm{~nm}$ \\
\hline
\end{tabular}

\subsection{Acute toxicity test in Rainbow trout fish}

The percent of mortality observed at the end of $96 \mathrm{hr}$ was $0,60,80,100$ and 20,60, 90, 100 at $0.1,1.0$, 10 and $100 \mathrm{mg} \mathrm{l}^{-1}$ concentrations for silver 1 and 2, respectively. No mortality was observed at a concentration of $0.01 \mathrm{mg} \mathrm{l}^{-1}$ for both the sizes of nano silver. Based on the mortality data, the $96 \mathrm{hr} \mathrm{LC}_{50}$ for tested nominal concentrations of silver nanoparticles 1 and 2 for Rainbow trout fish (O. mykiss) was determined to be $1.16 \mathrm{mg}$ $1^{-1}$ and $0.64 \mathrm{mg} \mathrm{l}^{-1}$ with confidence limits of $0.51-1.81 \mathrm{mg} \mathrm{l}^{-1}$ and $0.24-0.88 \mathrm{mg} \mathrm{l}^{-1}$, respectively (Fig-5). No behavioural abnormalities or toxicity signs were observed for both the sizes of silver at concentrations of 0.01 and $0.1 \mathrm{mg} \mathrm{l}^{-1}$. Pigmentation, loss of equilibrium, rapid opercular movement were observed in fishes treated with two different sizes of silver at $1.0,10,100 \mathrm{mg}^{-1}$ concentrations. No mortality and behavioural abnormalities were observed in all the test concentrations of MWCNT 1 and MWCNT 2 exposed fish. The $96 \mathrm{hr}$ $\mathrm{LC}_{50}$ of both the sizes of MWCNT could be considered as $>100 \mathrm{mg} \mathrm{l}^{-1}$.

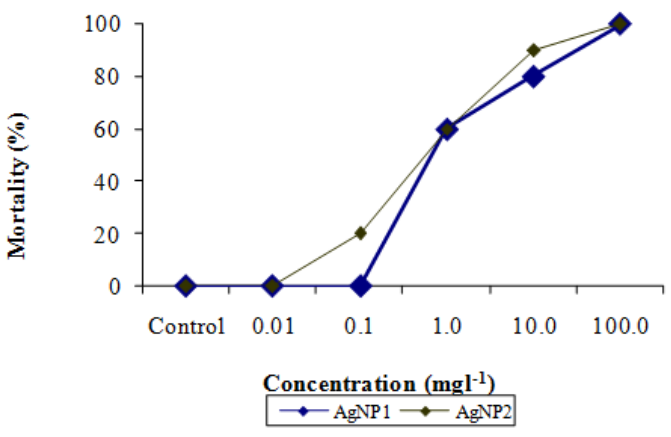

Figure 5: Acute toxicity test in Rainbow trout fish-Cumulative mortality of Silver 1 and 2 Nanoparticles at the end of 96 hours

\subsection{Acute immobilisation test in Daphnia}

Percentage of immobility exhibited at $48 \mathrm{hr}$ by Daphnia magna exposed to silver 1 at concentrations of $1,10,100 \mathrm{mg} \mathrm{l}^{-1}$ was 85,95 and 100 , respectively. At $0.1 \mathrm{mg} \mathrm{l}^{-1}$, no immobilisation was observed at $24 \mathrm{hr}$ interval while $40 \%$ immobilisation was recorded at the end of $48 \mathrm{hr}$. Daphnia exposed with silver 2, showed 5 , $65,90,100$ and 30, 90,100 and 100 percent immobility at concentrations of $0.1,1,10,100 \mathrm{mg} \mathrm{l}^{-1}$ at $48 \mathrm{hr}$. Based on the immobility data, the $48 \mathrm{hr} \mathrm{EC}_{50}$ for silver 1 and silver 2 for Daphnia magna was determined as $0.15 \mathrm{mg} \mathrm{l}^{-}$ ${ }^{1}$ and $0.22 \mathrm{mg} \mathrm{l}^{-1}$ with confidence limits of $0.1-0.2 \mathrm{mg} \mathrm{l}-1$ and $0.14-0.3 \mathrm{mg} / \mathrm{L}$, respectively (Fig- 6). At the end of $48 \mathrm{hr}$, no immobilisation was observed in daphnids exposed to all the concentrations of MWCNT 1 and MWCNT 2. The $48 \mathrm{hr} \mathrm{EC}_{50}$ for both the sizes of MWCNT could be considered as $>100 \mathrm{mg} \mathrm{l}^{-1}$.

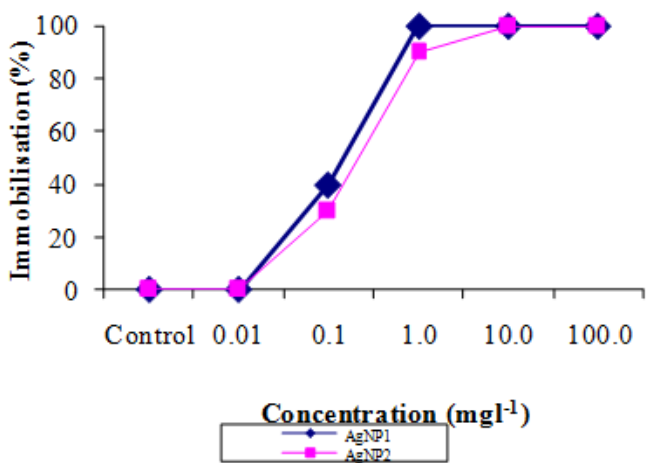

Figure 6: Acute Immobilasition test in Water flea- Immobilisation of Silver 1 and 2 Nanoparticles at the end of 48 hours 


\subsection{Alga Growth Inhibition Test}

The percent inhibition of yield and specific growth rate at $0-72 \mathrm{hr}$ for two different sizes of silver nanoparticles and MWCNT are presented in Table 2; Fig. $7 \&$ 8. The percent coefficient of variation of average specific growth rate during the entire test period $(72 \mathrm{hr}$ ) was less than $7 \%$, thereby satisfying the appropriate test acceptance criteria (OECD 201). The $72 \mathrm{hr} \mathrm{EC}_{50}$ values (95\% confidence limits) based on inhibition of growth and healthy cell counts are represented in Table $\mathbf{- 3}$.

TABLE 2: Effect of MWCNT and Silver nanoparticles on the yield and growth rate of $\boldsymbol{P}$. subcapitata

at $0-72 \mathrm{~h}$

\begin{tabular}{|c|c|c|c|c|c|c|c|c|}
\hline \multirow{4}{*}{$\begin{array}{l}\text { Concentrations } \\
\left(\mathrm{mg} \mathrm{l}^{-1}\right)\end{array}$} & \multicolumn{8}{|c|}{ Percent Inhibition } \\
\hline & \multicolumn{4}{|c|}{ Yield (\%) } & \multicolumn{4}{|c|}{ Specific growth rate $(\%)$} \\
\hline & \multicolumn{2}{|c|}{ MWCNT } & \multicolumn{2}{|l|}{ Silver } & \multicolumn{2}{|c|}{ MWCNT } & \multicolumn{2}{|l|}{ Silver } \\
\hline & Size 1 & Size 2 & Size 1 & Size 2 & Size 1 & Size 2 & Size 1 & Size 2 \\
\hline 0.01 & 1.77 & 0.18 & -1.79 & -1.29 & 0.3 & 0.0 & -0.3 & -0.2 \\
\hline 0.1 & 2.30 & 0.71 & -0.13 & -0.86 & 0.4 & 0.1 & 0.0 & -0.2 \\
\hline 100 & 99.64 & 97.52 & 99.74 & 99.28 & 90.2 & 66.9 & 90.8 & 82.0 \\
\hline
\end{tabular}

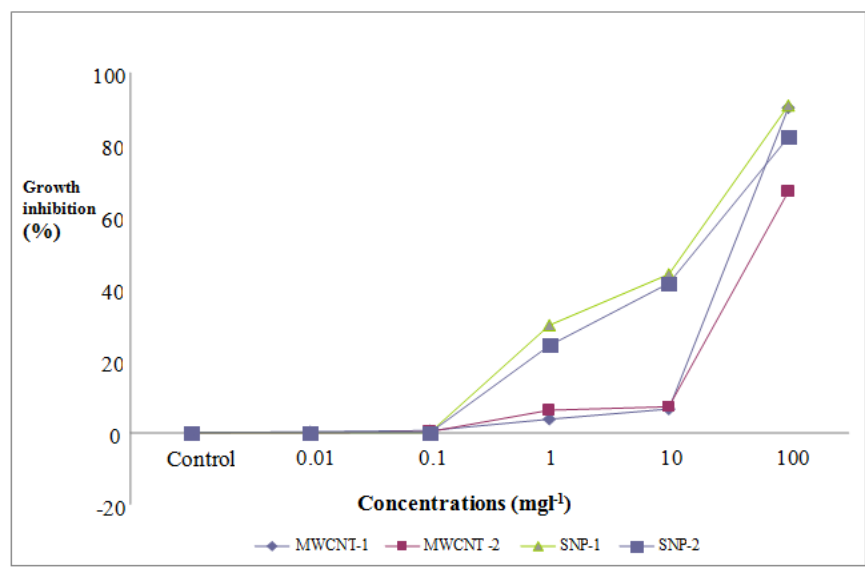

Figure 7: Inhibition of yield of Green Alga at 0 - 72hours

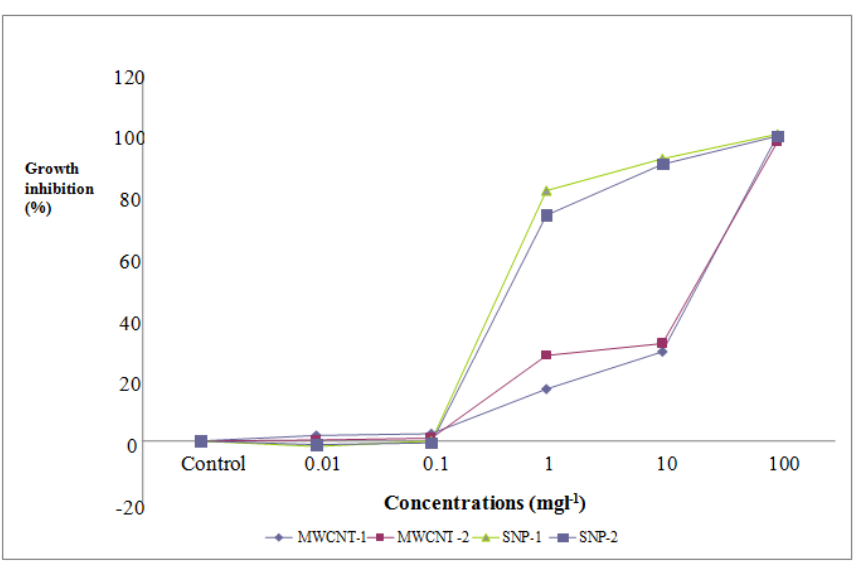

Figure 8: Inhibition of growth rate of Green Alga at 0 - 72hours 
TABLE 3: Toxicity of MWCNT and Silver nanoparticles on P. subcapitata

\begin{tabular}{|c|c|c|c|c|c|c|}
\hline \multirow[t]{2}{*}{ Materials Tested } & \multicolumn{2}{|c|}{$\begin{array}{l}E_{50} \text { values } \\
\left(\mathrm{mg} \mathrm{l}^{-1}\right)\end{array}$} & \multicolumn{2}{|c|}{$\begin{array}{l}\text { 95\% confidence limits } \\
\left(\mathrm{mg} \mathrm{I}^{-1}\right)\end{array}$} & \multirow{2}{*}{$\begin{array}{l}\text { NOEC } \\
\left(\mathrm{mg} \mathrm{l}^{-1}\right)\end{array}$} & \multirow{2}{*}{$\begin{array}{l}\text { LOEC } \\
\left(\mathrm{mg} \mathrm{l}^{-1}\right)\end{array}$} \\
\hline & $\mathrm{E}_{\mathrm{y}} \mathrm{C}_{50}$ & $\mathrm{E}_{\mathrm{r}} \mathrm{C}_{50}$ & $\mathrm{E}_{\mathrm{y}} \mathrm{C}_{50}$ & $\mathrm{E}_{\mathrm{r}} \mathrm{C}_{50}$ & & \\
\hline $\begin{array}{l}\text { MWCNT } \\
\text { (Size 1) }\end{array}$ & 12.45 & 38.27 & $11.41-13.59$ & $35.77-40.94$ & 0.1 & 1.0 \\
\hline $\begin{array}{l}\text { MWCNT } \\
\text { (Size 2) }\end{array}$ & 11.25 & 61.60 & $10.26-12.33$ & $56.54-67.11$ & 0.1 & 1.0 \\
\hline $\begin{array}{l}\text { Silver } \\
\text { Nanoparticles } \\
\text { (Size 1) } \\
\end{array}$ & 0.61 & 7.36 & $0.56-0.66$ & $6.60-8.20$ & 0.1 & 1.0 \\
\hline $\begin{array}{l}\text { Silver Nano } \\
\text { Particles (Size 2) }\end{array}$ & 0.76 & 11.54 & $0.70-0.82$ & $10.25-12.99$ & 0.1 & 1.0 \\
\hline
\end{tabular}

NOEC - No Observed Effect Concentration

LOEC - Lowest Observed Effect Concentration

\section{Discussion}

The scale of use of nanosilver, MWCNT and release of these wastes into the environment is increasing dramatically. An unprecedented number of nanosilver and MWCNT based consumer products used by perhaps millions of people will leach into the environment and cause potential damage to water ways, fish and other aquatic organisms. Therefore, we focused our attention on key aquatic species, viz. algae, Daphnia, fish and the data obtained with nanosilver showed high (H) concern (Smrchek et al., 1993; Wagner et al., 1995) towards aquatic species. The nanomaterials used in these studies were well chaecterized in dry state as well as in water. DLS was used to compare the primary particle size obtained with SEM/TEM to the average size and behavior in water. The size of the nanomaterials (MWCNT/silver) showed relatively increased size in water suggesting their tendency to form agglomerates. The formation of very strong nanomaterials aggregates due to van der Waals forces is expected to occur for unmodified carbon nanomaterials in solution, which is shown for the nano-sized carbon black nanoparticles, which have much larger sizes than their primary size (Murdock et al., 2008). The DLS results illustrate that depending on the material, once the nanomaterials are in solution they do not necessarily retain their "nano-size" Murdock et al., 2008.

In the present study, both the sizes of MWCNT did not show any toxicity to Rainbow trout fish and is of low concern (L). In a previous study also, Smith et al., (2007) reported that SWCNT's are a respiratory toxicant to Rainbow trout fish in a semi-static system and the fish were able to manage oxidative stress and osmoregulatory disturbances. Silver 1 nanoparticles revealed Medium Concern (M) in acute test while silver 2 nanoparticles, which are smaller in size than Silver 1 exhibited High Concern $(\mathrm{H})$. The mechanism of toxicity, it appears is manifested by blocking active absorption of sodium and chloride in addition causing sub lethal effects (Hogstrand and Wood, 1998). Theoretical considerations suggest that smaller particles are likely to be more toxic due to their larger specific surface area, which is conducive for greater bioavailability (SCENIHR 2005; Adams et al., 2006). In support of our results, previously reported studies suggest silver is toxic to fish, crabs, algae and other aquatic plants, as well as nitrogen fixing bacteria (Albright and Wilson 1974). Asharani et al., (2008) reported that silver nanoparticles have the potential to cause health and ecotoxicity issues in a concentration-dependent manner.

In the current study with Daphnia magna, using two different sizes of MWCNT we showed low concern (L), whereas both the sizes of silver nanoparticles exhibited High Concern (H). Zhu et al., (2009) reported that the toxicity of nanoparticles to D. magna may be due to the mechanical disruption of feeding appendages, penetration of the gutwall, and/or other physiochemical changes such as oxidative stress and/or cell death.

Algal growth inhibition test on the Green alga, Pseudokirchneriella subcapitata, exhibited Medium Concern (M) for MWCNT of both the sizes and High Concern $(\mathrm{H})$ to both the sizes of silver nanoparticles. In a previous study, Hiriart-Baer et al., (2006) reported that silver thiosulphate complexes can be transported across cell membranes in Chlamydomonas reinhardtii and P. subcapitata (two species of freshwater algae leading to increased toxicity. The silver nanoparticles exhibited high concern to algae when compared to MWCNT (medium concern) due to their anti-microbial properties. Nano-silver is an effective killing agent against a broad spectrum of gram-negative and gram-positive bacteria (Burrell et al., 1999; Yin et al., 2005), including antibiotic-resistant strains (Wright et al., 1998; Percival et al., 2007). 
Similarly, nano-silver is an effective and a fast-acting fungicide against a broad spectrum of common fungi including genera such as Aspergillus, Candida and Saccharomyces (Wright et al., 1999). Nanosilver may have a variety of fates in wastewater, including being converted into ionic form, forming a complex with other ions, molecules, or molecular groups, agglomerating (Limbach et al., 2007; Zhang et al., 2008) or remaining in nanoparticle form (Blaser et al., 2008).

\section{Conclusion}

The results of the present aquatic studies indicated that MWCNTs are low concern whereas silver nanoparticles are high concern to the aquatic species tested (Rainbow trout fish, Water flea and Green alga). Our studies demonstrated the adverse effects of silver nanoparticles to aquatic species. All applications involving silver nanoparticles should be given special attention and promoted only after detailed studies. Based on the above, potential ecotoxicities and environmental health effects of MNMs should not be neglected. As suggested by Zhu et al., (2009), approaches to testing of ecological and environmental effects should include representative MNMs from the major classes of commercial products (e.g., metal oxide and carbon based NPs tested herein), especially those that are most likely to be released into aquatic environments. In conclusion, the release of nano waste into the environment should be restricted for the well-being of human and aquatic species.

\section{Acknowledgements}

The authors are grateful to the IIBAT management for providing support for this work. We thank Mr. A. Goparaju, statistician for helping in analysis of data.

\section{References}

[1] Colvin L, The potential environmental impact of engineered nanomaterials, Nature biotechnology, 21, 2003, 1166-1170.

[2] Oberdorster G, Oberdorster E and Oberdorster J, Nanotoxicology an emerging discipline evolving from studies of ultrafine particles. Environ. Health Perspect. 113, 2005, 823-839.

[3] US EPA, Nanotechnology White Paper Science Policy Council, Nanotechnology Workgroup. Report No: EPA 100-B-07-001, 132 pp, Feb 2007 US EPA Nanotechnology White Paper [displayed February 2007] http://es.epa.gov/ncer/nano/ publications/whitepaper12022005.pdf

[4] Oberdorster E, Zhu S, TM, Blickley P, McClellan-Green and ML, Haasch, Ecotoxicology of carbon-based engineered nanoparticles: effects of fullerene (C60) on aquatic organisms. Carbon. 44, 2006, 1112-1120.

[5] Templeton R., Leeferguson P, Washburn K, Scrivens W and Thomaschandler G, Life-cycle effects of single-walled carbon nanotubes (SWNTs) on an estuarine meiobenthic copepod. Environ Sci Technol. 40, 2006, 7387- 7393.

[6] Roberts AP, Mount AS, Seda B, Souther J, Qiao R, Lin S, Ke PC, Rao, AM and Klaine SJ, In vivo biomodification of lipidcoated carbon nanotubes by Daphnia magna. Environ Sci Technol. 41, 2007, 3025-3029.

[7] Smith CJ, Shaw BJ and Handy RD, Toxicity of single walled carbon nanotubes to rainbow trout, (Oncorhynchus mykiss): respiratory toxicity, organ pathologies, and other physiological effects. Aquat Toxicol. 82, 2007, 94-109.

[8] Hund-Rinke, K and Simon M, Ecotoxic effect of photocatalytic active nanoparticles (TiO2) on algae and daphnids. Environ Sci Pollut Res 13, 2006, 225-232.

[9] Adams LK, Lyon DY, McIntosh A and Alvarez PJJ, Comparative eco-toxicity of nano-scale TiO2, SiO2 and ZnO water suspensions. Water Res., 40, 2006, 3527-3532.

[10] Zhu X, Zhu L, Li Y, Qi R, Duan RZ and Lang YP, Comparative toxicity of several metal oxide nano-particle aqueous suspensions to Zebra fish (Danio rerio) early developmental stage. J Environ Sci Health A, 43, 2008, 278-284.

[11] Scientific Committee on Emerging and Newly Identified Health Risks (SCENIHR), 2005, http://ec.europa.eu/comm/health/ph risk/committees/04 scenihr/04 scenihr en.htm.

[12] Service RF, Is nanotechnology dangerous? Science. 290, 2000, 1526-1527.

[13] Service RF, Nanomaterials show signs of toxicity. Science. 300, 2003, 243-243.

[14] Nel A, Xia T, Madler L and Li N, Toxic potential of materials at the nanolevel. Science 311, 2006, $622-627$.

[15] Sairam Kishore A, Surekha P and Balakrishna Murthy P, Assessment of the dermal and ocular irritation potential of multi-walled carbon nanotubes by using in vitro and in vivo methods. Toxicology Letters, 191, 2009, 268-274.

[16] Murdock RC, L. Braydich-Stolle AM, Schrand JJ, Schlager, and Hussain SM, Characterization of Nanomaterial Dispersion in Solution Prior to In Vitro Exposure Using Dynamic Light Scattering Technique. Toxicol.Sci. 101, 2008, 239-253.

[17] Organisation for Economic Co-operation and Development (OECD) (1992) Guideline for the Testing of Chemicals: (Part 203).

[18] APHA: Standard Methods for examination of water and wastewater 14th Edn. APHA, AWWA, WPCF, Washington DC. 1975.

[19] Organisation for Economic Co-operation and Development (OECD) (2004) Guideline for the Testing of Chemicals: (Part 202).

[20] Organisation for Economic Co-operation and Development (OECD) (2006) Guideline for the Testing of Chemicals: (Part 201).

[21] Smrchek JC, Clements R, Morcock R and Robert W, Assessing Ecological Hazards under TSCA, Methods and Evaluation of Data.” Environmental Toxicology and Risk Assessment. ASTM STP 1179. Wayne G. Landis, Jane S. Hughes, and Michael A. Landis (Eds.). American Society for Testing and Materials, Philadelphia, 1993, 22-39.

[22] Wagner PM, Nabholz JV, and Kent RJ, The New Chemicals process at the Environmental Protection Agency (EPA) StructureActivity Relationships for Hazard Identification and Risk Assessment.” Toxicology Letters, 79, 1995, 67-73.

[23] Hogstrand C and Wood CM, Toward a better understanding of the bioavailability, physiology, and toxicity of silver in fish, Implications for water quality criteria. Environ Toxicol Chem, 17, 1998, 547-561.

[24] Albright LJ and Wilson EM, Sub-lethal effects of several metallic salt organic compound combinations upon heterotrophic microflora of a natural water. Water Res., 8, 1974, 101-105.

[25] Asharani PV, Yi Lian, Wu, Zhiyuan Gong and Suresh Valiyaveettil, Toxicity of silver nanoparticles in Zebra fish models. Nanotechnology 19, 2008

[26] Zhu, Lin Zhu, Yongsheng Chen and Shengyan Tian, Acute toxicities of six manufactured nanomaterial suspensions to Daphnia magna. J Nanopart Res, 11, 2009, 67-75. 
[27] Hiriart-Baer VP, Fortin C, Lee DY and Campbell PGC, Toxicity of silver to two freshwater algae, Chlamydomonas reinhardtii and Pseudokirchneriella subcapitata grown under continuous culture conditions: Influence of thiosulphate. Aquatic Toxicol. 78, 2006, 136-148.

[28] Burrell RE, Heggers JP, Davis GJ and Wright JB, Efficacy of silver-coated dressings as bacterial barriers in a rodent burn sepsis model. Wounds. 11, 1999, 64-71.

[29] Yin H, Too HP and Chow GM, The effect of particle size and surface coating on the cytotoxicity of nickel ferrite. Biomaterials. 26, $2005,5818-5826$.

[30] Wright JB, Lam K and Burrell RE, Wound management in an era of increasing bacterial antibiotic resistance: A role for topical silver treatment. Am J Infect Control, 1998, 26, 572-577.

[31] Percival SL, Bowler PG and Dolman J, Antimicrobial activity of silver-containing dressings on wound microorganisms using an in vitro biofilm model. Int Wound J. 4, 2007, 186-191.

[32] Wright JB, Lam K, Hansen D and Burrell RE, Efficacy of topical silver against fungal burn wound pathogens. Am J Infect Control. $27,1999,344-350$.

[33] Limbach L, Wick P, Manser P, Grass R, Bruinink A and Stark W, Exposure of engineered nanoparticles to human lung epithelial cells Influence of chemical composition and catalytic activity on oxidative stress. Env Sci \& Tech. 41, 2007, 4158-4163.

[34] Zhang JY, Mitroy J, Sadeghpour HR and Bromley MWJ, Long-range interactions of copper and silver atoms with hydrogen, helium and rare-gas atoms. Phys. Rev. A, 78, 2008.

[35] Blaser SA, Scheringer M, MacLeod M and Hungerbühler K, Estimation of cumulative aquatic exposure and risk due to silver: Contribution of nanofunctionalized plastics and textiles. Science of the total environment. 390, 2008. 